\title{
Brief Commentary
}

\section{e Ulnar Tunnel Syndrome with Ultrasonographic Nerve Imaging}

Elif Yalcin, MD', Mufit Akyuz, MD'1, and Ece Unlu, MD²

From: ${ }^{1}$ Department of Physical Medicine and Rehabilitation, Ankara Physical Medicine \& Rehabilitation Training and Research Hospital of the Ministry of Health, Ankara, Turkey; ${ }^{2}$ Ankara Diskapi Yildirim Beyazit Training and Research Hospital of the Ministry of Health, Ankara, Turkey.

Address Correspondence: Elif Yalcin, MD Ankara Fizik Tedavi Rehabilitasyon Egitim ve Arastırma Hastanesi Turkocagı Sokak Sihhiye-Ankara-Turkey E-mail: elifyalcin78@gmail.com

Disclaimer: There was no external funding in the preparation of this manuscript.

Free full manuscript: www.painphysicianjournal.com
A 32-year-old man presented to our clinic complaining of numbness of the little finger and the ulnar aspect of the ring finger of his right hand. He complained about the weakness of grip strength and ulnar-sided pain. At the first glance, wasting of the first interossei muscle could be recognized. In his detailed examination, the medial half of the palmar aspect of the hand, including the hypothenar eminence, along with the palmar side of the fourth and fifth digits showed decreased sensation to light touch. Severe weakness of the abductor digiti minimi (ADM) was noted. No sensory loss was found in the dorsum of the hand, excluding the diagnosis of ulnar neuropathy at the elbow.

By ultrasonographic evaluation (using a linear array probe, $7-12 \mathrm{MHz}$ Logiq $\mathrm{P} 5 \mathrm{a})$, the ulnar nerve was observed to be enlarged in the ulnar tunnel at the medial side of pisiform (Fig. 1). No compressive lesions such as ganglion or cysts were seen at the level of nerve enlargement. The electrophysiologic evaluation also confirmed the ulnar neuropathy at the guyon level.

The most frequent causes of guyon neuropathy are space-occupying lesions such as ganglia, hematoma, or cysts, and repetitive trauma such as cycling. The treatment options would differ according to the etiological factors. If it is a mass lesion caused compression, surgical intervention should be applied. If the syndrome results from mechanical repetitive trauma, the treatment approach would be avoid-

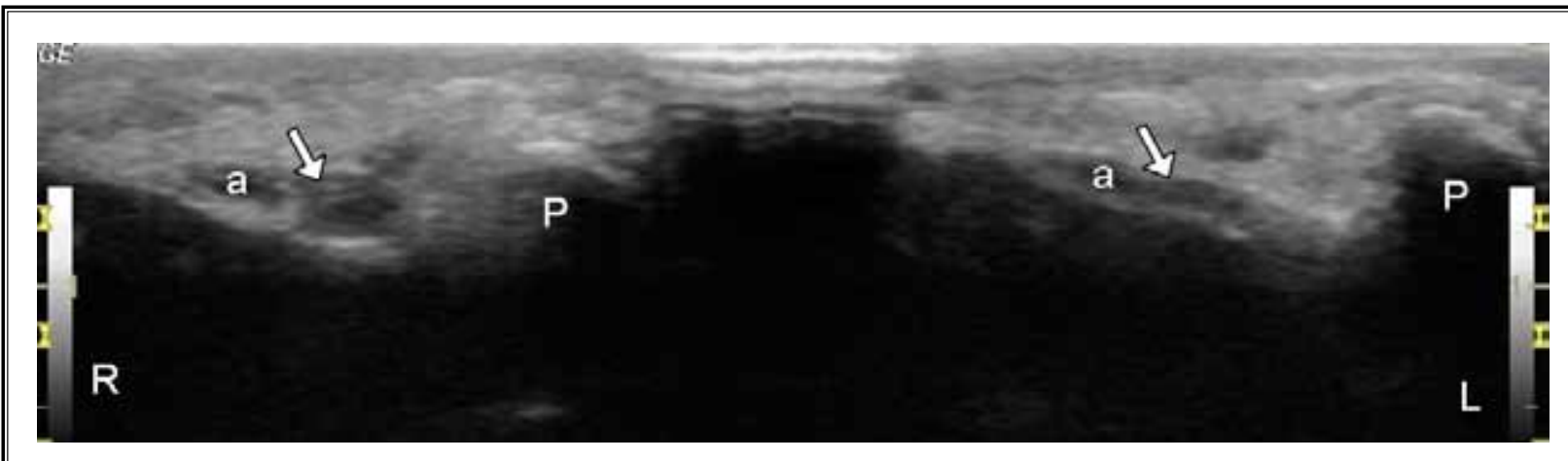

Fig. 1. Ultrasonographic imaging (axial view) of both ulnar nerves at the ulnar tunnels (arrows), demonstrating enlargement of the ulnar nerve on the right side. P: pisiforme bone, a: ulnar artery. 
ing the repetitive stress on the hypothenar eminence (1).

In daily practice, prompt imaging of the peripheral nerve just before the electrodiagnostic studies could facilitate the diagnostic procedure. Ultrasonographic evaluation could also help to decide the appropriate treatment approach in entrapment neuropathies (2). In detailed anamnesis, our patient claimed the repetitive compression to the ulnar side of his hand was due to his job (using a drill). Avoidance of provocative activities and rest were recommended as treatment. Six weeks later the symptoms were relieved and later on, the atrophy of the first interossei muscle began to improve.

Ultrasonographically, the ulnar nerve can be seen between the ulnar artery and medial bony acoustic landmark of the pisiform at the guyon canal. At this position the ulnar tunnel is bordered superiorly by the palmar carpal ligament and the floor of the tunnel is the transverse carpal ligament. In this area, the nerve should be assessed for focal enlargement and echotexture change both with short axis and long axis images. Comparison of muscle echotexture of ulnar innervated muscles with both the contralateral side and the neighboring median innervated muscles can be also helpful for the diagnosis of ulnar neuropathy in this region (1).

In daily practice, prompt imaging of the peripheral nerve just before electrodiagnostic studies could facilitate the diagnostic procedure and the treatment approach.

\section{References}

1. Strakowski JA. Evaluation of ulnar nerve. In: Ultrasound Evaluation of Focal Neuropathies Correlation with Electrodiag- nosis. Demos Medical Publishing, Ohio, 2014, pp 269-311.

2. Kara M, Özçakar L, De Muynck M, Tok F,
Vanderstraeten G. Musculoskeletal ultrasound for peripheral nerve lesions. Eur] Phys Rehabil Med 2012; 48:665-674. 